\title{
Use of Project-based Training in Teaching Business Translation
}

\author{
Belqes Al-Sowaidi
}

\section{ABSTRACT}

\begin{abstract}
The present study reports on the use of project-based learning in teaching business translation at the undergraduate level at two Yemeni universities; namely, Al-Saeed University and Taiz University. Two groups of students, one control and the other experimental, were selected. Both groups took a pre-test in business translation in which they were asked to translate several texts from Arabic into English, and vice versa. After the pre-test, the two groups completed a 3-month business translation course. Project-based translation training was used with the experimental group. The control group covered the content of the course in a traditional manner. Both groups were asked to take a post-test in business translation after completion of the course. The study concluded that the experimental group that completed the project-based training showed more progress than the control group. The difference between the mean of the two groups was found to be significant, at $p<0.05$. Members of the experimental group were also interviewed about the project-based approach adopted in the programme to gain insights into its pros and cons.
\end{abstract}

Keywords: Arabic, business, English, project-based, training, translation.
Published Online: August 15, 2021

ISSN: $2736-4534$

DOI :10.24018/ejedu.2021.2.4.114

\section{Belqes Al-Sowaidi*}

Associate professor, Center of Languages and Translation, Taiz University, Yemen \& a research fellow of the University of the Western Cape, South Africa.

(e-mail: kenani204212@gmail.com)

*Corresponding Author

\section{INTRODUCTION}

Translation pedagogy has gained a lot of attention within the multidisciplinary field of translation studies. It has therefore benefited from the theoretical and practical approaches used in neighbouring fields such as psychology, language teaching, and the like. As a result, translation institutions today use various educational assessment and teaching approaches that have been previously used in other areas of study. The adoption of such robust methodologies is essential for the successful graduation and employability of student translators. The competence of the student translators can be enhanced by utilizing well-established teaching methodologies in other disciplines. Among these methodologies, project-based learning is highly beneficial for the would-be translator and for the development of their expertise, which starts when they begin a translation programme at a university.

Translating a text does not only imply the use of a dictionary to search for new terms. It is a sophisticated act that includes linguistic, extralinguistic, cultural, technological, and psychological competence. Involving translators in different projects allows them to sharpen their skills and have a greater impact on their motivation, achievement, and self-efficacy. Project-based learning in the context of translation training is not confined to the translation of different types of texts and genres, such as news and media texts, or medical texts in a traditional or virtual classroom. It can involve translation projects as part of internships, voluntary translation of software, and collaborative translation of Massive Online Open Courses
(MOOCs). Translation can also be employed effectively in website localisation and subtitling and dubbing. A translator may be required to translate genres or text types with which he/she is not familiar. It is necessary therefore to prepare student translators to deal with various text types and to train them linguistically, technologically, and psychologically to meet the demands of the industry. Undoubtedly, projectbased learning can contribute towards the effective training of tomorrow's translators.

This paper reports on the use of project-based learning in the teaching of an advanced business translation courses at two Yemeni universities. namely, Al-Saeed University and Taiz University. The courses aim to teach business translation with the help of modern technologies in a project-based approach with the aim of discerning the extent to which this project-based approach to translation teaching enhances the translation competence of student translators.

In this paper, the term 'project-based training' is used in its broadest sense to refer to a work plan or a thoroughgoing approach that targets the act of translation, links it to realworld endeavours, prioritizes project completion, and evaluates outcomes [1].

\section{RESEARCH QUESTIONS AND HYPOTHESES}

The current study examines the relationship between the use of project-based learning and the enhancement of students' competence while translating business texts from English into Arabic and vice versa. To be more precise, the study attempts to answer the following two questions: 
1. What is the impact of project-based training on students' translation competence?

2. What are students' perceptions regarding the use of project-based training in their business translation course?

Based on the relationship between project-based training and students' translation competence as a way of determining the influence of an experimental approach, a null hypothesis and an alternative one have been formulated. The null hypothesis is stated as follows, H0:

Project-based training has no impact on students' translation competence. The alternate hypothesis is, H1: Applying project-based training has a significant impact on students' translation competence.

\section{LITERATURE REVIEW}

Project-based training for translation studies has not been adequately investigated in the classroom. Few studies have explored the benefits of this method in training translators. For example, project-based learning was used in the teaching of a computer-aided translation technology course in a Saudi context. The study used interviews to collect data and investigate the attitudes of the trainees towards training approaches. It concluded that project-based learning is beneficial insofar as the autonomy of student translators is concerned. However, some students expressed their dissatisfaction with the time allocated for projects as well as some issues with practicality [2]. Another study on the use of project-based learning in a computer-assisted translation course concluded that it is a constructivist approach that empowers trainee translators and enables them to solve problems which reflect those encountered in the language and translation industry. A constructivist approach encourages professional behaviour and enables learners to develop skills beyond the mere use of computer-assisted translation tools [3]. Project-based learning was also used in the teaching of some cloud-based computer assisted translation tools such as Memsource. The tool was used in projects done by students of the MA module "Languages and Business Relations" at the University of Aveiro, Portugal. The study supported the findings of other studies which found that project-based learning equips students with a multidisciplinary competence, improves their linguistic proficiency, and encourages them to actively participate in decision-making and problem-solving processes [4].

Project-based learning was also used in the training of audio-visual translators. For instance, the model was used for training subtitling trainees in a course for audio-visual translation at the Institute of Applied Linguistics at the University of Warsaw, Poland. The course was offered as an elective module in the MA Programme in Translation [5].

Similarly, a project-based learning approach was also implemented in the teaching of automated translation at the College of Languages and Translation at Imam Muhammad Ibn Saud Islamic University, Riyadh, Saudi Arabia. Forty graduate students participated in the study. A questionnaire, translation elicitation tasks, and exam results were used to collect the data. The students were divided into two groups. The first group was taught using a traditional approach, and project-based learning was used with the second group. The comparison of the final exam results of the two groups and assignments were analysed statistically. The findings showed that the project-based teaching approach has a greater impact on students' performance [6].

The perceptions of the students towards the use of projectbased learning $(\mathrm{PjBL})$ for teaching business translation in a Chinese context was also investigated in a recent study. The findings of the study showed that the students had positive attitudes towards the introduction and use of project-based learning[7]. Similarly, the attitudes of trainee translators towards the project-based learning in an Indonesian-English translation class showed that the use of project-based learning improved the autonomy of the learners, their critical thinking, and their attitudes towards collaboration with peers. The study also reported some obstacles, such as the limited time for preparation, adaptation to new group members, and the location of projects that took place off-campus[8]. Insofar as syllabus design is concerned, a project-based flipped learning model for teaching an English to Chinese business translation course was designed [9]. Sixty-five students in their third year of study participated in an empirical study to test the efficacy of the programme. The participating students were divided into an experimental and a control group. The translation projects were prepared, and students were divided into an experimental class and a client group. Each unit in the course used three translator groups. A post-test was also conducted at the end of the semester. Data was also collected through interviews and questionnaires from both groups. The study concluded that the adopted model motivated the learners, stimulated their participation in class, and enhanced their translation competence. The study also found that the product-oriented summative assessment model, which is widely used in traditional classes, is ineffective and therefore opted for a process-oriented assessment model [9]. The impact of project-based learning on trainee translators between Persian and English was also investigated. The approach was applied during an advanced translation course at an Iranian university. Twenty-one students participated in the study. The study concluded that critical thinking, teamwork performance and other related skills, as well as the translation quality of trainee translators showed a clear improvement after the treatment [10].

The various benefits of project-based learning in a translation training context were also explored in another study by S. Bell [11]. The findings of the study indicated that project-based learning enhanced collaboration among trainees and enabled them to work on projects in line with future career prospects. In addition, project-based learning is significant for enhancing technology, problem-solving, and communication skills. Situated learning, which is another version of project-based learning, was also used in translator training. Situated learning plays a key role in the development of translation competence in general and instrumental or technological sub-competence and professional subcompetence in particular, which was explored in a study by M. González-Davies and V. Enríquez-Raído [12]. The study indicated that this type of learning is useful for translators as it encourages them to develop workplace-related knowledge and solve problems they are likely to encounter in a professional setting. The study also showed that the trainee translators were taught to use some web 2.0 tools in their 
translation tasks. The use of such tools enabled them to develop their instrumental competence, facilitated collaboration and interaction, and improved learning performance and the autonomy and confidence of the trainee translators.

The significance of project-based learning in the development of generic competencies of trainee translators was also highlighted in a recent study [13]. The study emphasized the need to focus on the generic competence of the translator. The study noted that so far, the acquisition and development of translation competence have taken place through formal training in a tertiary education context, such as universities and colleges. Most of the time the training focuses on enhancement of subject-specific competence. The study recommended the use of project simulation with the aim of enhancing the generic competencies of trainee translators. This results in a hybridisation of subject-specific competencies and generic competencies in translator education.

The present study investigates the significance of the project-based learning in the context of Arabic-English business translation at two Yemeni universities. To the best of the researcher's knowledge, no previous studies have attempted to highlight the validity of this approach while teaching business translation in Yemeni and Arab contexts.

\section{THEORETICAL FRAMEWORK}

Project-based learning (PBL) is a student-centred approach widely used in various fields of study including translation training. The approach assumes that students or trainees learn best by doing. That is, students are involved in real-world projects for an extended period. It is therefore based on the concepts of active and engaged learning. Learners are productive participants in the learning process, and they are no longer passive recipients of knowledge. Students work autonomously and collaboratively to construct their learning. The role of the teacher is therefore one of facilitator. Projects provide students with the opportunity to explore, assess, interpret, and synthesise information with a view to achieve various types of learning outcomes (i.e., knowledge, skills, attitudes, etc.).

Markham (2011:38) summarises the core features of project-based learning saying that it "integrates knowing and doing. Students learn knowledge and elements of the core curriculum, but also apply what they know to solve authentic problems and produce results that matter. PBL students take advantage of digital tools to produce high quality, collaborative products" [14].

One underlying principle of project-based learning is the ownership of learning. Students are likely to find projects more motivating and take responsibility for their own learning. Instead of overreliance on the lecturers, students carry out projects independently by organising group learning activities, carrying out assessments or research, solving problems, and synthesising information [8]. They take full responsibility over the production cycle from preparation and pre-translation to production and delivery of the project to the client.

Unlike traditional learning, project-based training addresses real-life issues, fosters the critical thinking of trainees, promotes deep learning and requires continuous reflection on a task, challenge or problem [11], [15], [16]. In addition, projects are likely to develop students' confidence and self-discipline. Projects provide them with an opportunity to acquire and improve their organisational and research skills, develop communication and collaboration skills with their peers, and negotiations skills with clients. In the process of implementation of a project, students can use a myriad of technological tools and equipment in the various stages of translation. As Bell (2010: 42) points out:

An authentic use of technology is highly engaging to students because it taps into their fluency with computers. Students participate in research using the internet. During this phase of PBL, students learn how to navigate the internet judiciously, as well as to discriminate between reliable and unreliable sources [11].

Assessment in such projects is another positive factor. Students are mostly assessed based on their various roles in the project and not on their scores in a written exam or summative tasks.

Project-based training "refocuses education on the student, not the curriculum, which rewards intangible assets such as drive, passion, creativity, empathy, and resiliency. These cannot be taught out of a textbook, but must be activated through experience" [14]. That experience is something that project-based learning can give to students and teachers.

Project-based learning in translation pedagogy is therefore inspired by learning theories that have been adopted in various fields including social-constructivism, post modernism, self-directed learning, enactive cognitive science, complexity theory, transformational educational theory, and the capability approach [15], [17].

\section{Methodology}

This study employs mixed qualitative and quantitative methods for the collection of data. To be more precise, preand post-tests for a control group and an experimental group were used. The participants of the latter were also interviewed after the completion of the course in business translation, and after the completion of the post-test.

\section{A. Participants}

The participants in this study included twenty Yemeni fourth-year students in the departments of English at AlSaeed University, and Taiz University, both in Taiz in Yemen. The participating students from the former constitute the total number of students. However, the participants from Taiz University were selected from the population of twentythree students enrolled in an advanced translation course at the university. The age of the students ranges from twentytwo to twenty-three years.

\section{B. Instrumentation}

To answer the first research question, "What is the impact of project-based training on students' translation competence?", a quasi-experimental investigation with a pretest-posttest control group design was conducted in the beginning and at the end of the course. The course was 
offered in the first semester of the academic year 2017-2018, with students from both universities. The students were provided with protocols for pre-testing their abilities in translation and for post-testing the same competencies. Students were involved in several elicitation tasks and translation projects throughout the course. Some of the projects include the translation of a business letter, a commercial website, a user manual, food labels, Halal industry promotional materials, and an academic lecture. The tasks and projects were administered by the researcher, who played the role of an instructor.

The quantitative data are complemented with qualitative interviews which provide interesting insights into the students' perceptions of the implementation of project-based learning. For the second qualitative part of this mixed methods research, an interview protocol was used to collect the students' perceptions of project-based training. The interviews included questions on students' thoughts regarding the effect of project-based learning on developing their translation competence. The participants were interviewed face-to-face in the last week of the course, and their answers were recorded and transcribed during the discussion of the findings.

\section{Procedure}

In the beginning of the course, all participants were asked to do a pre-test in which they were asked to translate several texts from Arabic into English. Based on the initial screening of their translations and their scores in the pre-test, the participants demonstrated similar comprehensive learning abilities.

After the pre-test, the students were divided into an experimental group, which included all participants from AlSaeed University, and a control group, which included the students from Taiz University. During the implementation of the course, project-based training sessions were utilised in the course for the experimental group. Traditional learning sessions were adopted for the participants of the control group.

Both groups of students received a three-hour weekly session during the ten-week experimentation period. The sessions for the members of the control and experimental groups differed only in the presence of projects for students in the latter. Each week, the students were requested to translate texts of various length and difficulty about different business-related themes. They did some of the tasks in groups or in pairs during class, and some as take-home assignments. Members of the experimental groups, however, were asked to participate in some structured projects in addition to the core content of the course. The projects were real-life assignments; students were commissioned to translate content for real companies or organizations, and they were required to follow the standards of the translation industry from preparation to delivery. Students completed four projects during the course. They were also given specific training and tutorials on the use of various computer-assisted translation tools and localisation software. At the end of the course, both groups took a posttest in business translation. In addition, the participants from the experimental group took part in individual interviews to assess their perceptions of the project-based learning sessions. They were also asked to share their opinions regarding any observed changes in their translation competencies. The answers to these questions were used by the researcher for analysing students' perceptions and responding to the second research question.

\section{FINDINGS AND DISCUSSION}

This section presents a summary of the findings from the pre and post-tests of the two groups as well as the findings from the interviews with the members of the experimental group.

\section{A. Pre-test and Post-test Findings}

The pre and post-test scores of both groups were collected and analysed by the Statistical Package for the Social Sciences (SPSS) software. The statistical significance was analysed using various statistical tests including descriptive statistics, analysis of variance, $t$-tests, and one-way ANOVA as appropriate. Firstly, descriptive statistics and the results of $t$-tests were calculated for the control and experimental groups to determine any differences in their performance in the pre-test. Table I presents the descriptive statistics with reference to the scores received after completing the translation pre-test.

TABLE I: DESCRIPTIVE STATISTICS FOR THE PRE-TEST IN BUSINESS TRANSLATION

\begin{tabular}{cccccccc}
\hline \multicolumn{8}{c}{ Valid cases = 20; cases with missing value(s) $=10$} \\
\hline \multirow{2}{*}{ Variable } & \multirow{2}{*}{ N } & Mean & $\begin{array}{c}\text { Std } \\
\text { Dev }\end{array}$ & Skewness & $\begin{array}{c}\text { S.E. } \\
\text { Skew }\end{array}$ & Minimum & Maximum \\
\hline Pretest C & 10 & 68,90 & 3,35 & 0,02 & 0,69 & 64,00 & 75,00 \\
Pretest E & 10 & 69,10 & 2,96 & $-0,31$ & 0,69 & 64,00 & 74,00 \\
\hline
\end{tabular}

Table I above shows the descriptive statistics results of the pre-test for both control and experimental groups. The mean scores identified for the translation pre-test for the experimental and control groups are 69.10 and 68.90, respectively, with standards deviations of 3.35 and 2.96 , respectively. The difference is less than one point. Table II provides the results of an independent sample $t$-test that was conducted to examine the statistical significance in the mean score for the two groups on pre-testing.

The results of Levene's test indicate that the $F$ value is 0.24 , where $p=0.627>0.05$. Therefore, the variances between the examined groups were not significantly different statistically. In addition, the results of the $t$-test, where $t=-0,14$ and $p=0.889>0.05$, indicate that the difference between the mean scores is not statistically significant. Table III provides the descriptive statistics details with reference to the scores that were received after completing the post-test in translation.

The results indicate that the difference in the mean scores determined for the post-test in translation, for both the experimental and control groups (76.70 and 70.10, respectively), was about six points. The $t$-test was conducted to determine the existence of the statistical significance in these findings. Table IV includes the results of an independent sample $t$-test that was calculated for the two groups on post-testing in translation. 
TABLE II: INDEPENDENT SAMPLE T-TEST FOR THE PRE-TEST IN BUSINESS TRANSLATION

\begin{tabular}{|c|c|c|c|c|c|c|c|c|c|c|}
\hline \multicolumn{11}{|c|}{ Independent Samples Test } \\
\hline & & & & \multicolumn{7}{|c|}{ t-test for Equality of Means } \\
\hline & & \multicolumn{2}{|c|}{$\begin{array}{c}\text { Levene's Test for Equality } \\
\text { of Variances }\end{array}$} & \multirow[t]{2}{*}{$\mathrm{t}$} & \multirow[t]{2}{*}{ df } & \multirow{2}{*}{$\begin{array}{l}\text { Sig. }(2- \\
\text { tailed) }\end{array}$} & \multirow{2}{*}{$\begin{array}{c}\text { Mean } \\
\text { Difference }\end{array}$} & \multirow{2}{*}{$\begin{array}{l}\text { Std. Error } \\
\text { Difference }\end{array}$} & \multicolumn{2}{|c|}{$\begin{array}{c}95 \% \text { Confidence Interva } \\
\text { of the Difference }\end{array}$} \\
\hline & & $\mathrm{F}$ & Sig. & & & & & & Lower & Upper \\
\hline \multirow[t]{2}{*}{ pretest } & $\begin{array}{l}\text { Equal variances } \\
\text { assumed }\end{array}$ & 0,24 & 0,627 & $-0,14$ & 18,00 & 0,889 & $-0,20$ & 1,41 & $-3,17$ & 2,77 \\
\hline & $\begin{array}{c}\text { Equal variances } \\
\text { not assumed }\end{array}$ & & & $-0,14$ & 17,73 & 0,889 & $-0,20$ & 1,41 & $-3,17$ & 2,77 \\
\hline
\end{tabular}

TABLE IV: INDEPENDENT SAMPLE $T$-TEST FOR THE POST-TESTING IN BUSINESS TRANSLATION Independent Samples Test

\begin{tabular}{|c|c|c|c|c|c|c|c|c|c|c|}
\hline & & \multirow{2}{*}{\multicolumn{2}{|c|}{$\begin{array}{c}\text { Levene's Test for } \\
\text { Equality of Variances }\end{array}$}} & \multicolumn{7}{|c|}{ t-test for Equality of Means } \\
\hline & & & & \multirow[t]{2}{*}{$\mathrm{t}$} & \multirow[t]{2}{*}{ df } & \multirow{2}{*}{$\begin{array}{l}\text { Sig. }(2- \\
\text { tailed) }\end{array}$} & \multirow{2}{*}{$\begin{array}{c}\text { Mean } \\
\text { Difference }\end{array}$} & \multirow{2}{*}{$\begin{array}{l}\text { Std. Error } \\
\text { Difference }\end{array}$} & \multicolumn{2}{|c|}{$\begin{array}{l}95 \% \text { Confidence Interval of } \\
\text { the Difference }\end{array}$} \\
\hline & & $\mathrm{F}$ & Sig. & & & & & & Lower & Upper \\
\hline \multirow[t]{2}{*}{ Difference } & $\begin{array}{c}\text { Equal variances } \\
\text { assumed }\end{array}$ & 4,89 & 0,040 & $-4,30$ & 18,00 & 0,000 & $-5,80$ & 1,35 & $-8,64$ & $-2,96$ \\
\hline & $\begin{array}{c}\text { Equal variances not } \\
\text { assumed }\end{array}$ & & & $-4,30$ & 11,94 & 0,001 & $-5,80$ & 1,35 & $-8,74$ & $-2,86$ \\
\hline
\end{tabular}

TABLE III: DESCRIPTIVE STATISTICS FOR THE POST-TEST IN BUSINESS TRANSLATION

Valid cases $=20$; cases with missing value $(s)=10$

\begin{tabular}{cccccccc}
\hline Variable & N & Mean & $\begin{array}{c}\text { Std } \\
\text { Dev }\end{array}$ & Skewness & $\begin{array}{c}\text { S.E. } \\
\text { Skew }\end{array}$ & Minimum Maximum \\
\hline Posttest C & 10 & 70,10 & 2,85 & 0,67 & 0,69 & 66,00 & 76,00 \\
Posttest E & 10 & 76,70 & 2,50 & 1,12 & 0,69 & 74,00 & 82,00 \\
\hline
\end{tabular}

According to the results of Levene's test, the F value is 4.89 , where $\mathrm{p}=0.000<0.05$. Thus, the variances between the examined groups were significantly different in this case. The results of the t-test, where $t=-4.30$ and $p=0.000<0.05$, indicate that a particular difference between the mean scores of the two groups of participants is statistically significant. Comparing the results for pre- and post-testing in translation, the experimental group demonstrated statistically significant improvement in the mean score of about 7.6 points in comparison to the pre-test results, and one point in comparison to the control group after receiving the treatment. To check that the difference is the outcome of the treatment, a one-way ANOVA test, as shown in Table V, was conducted.

Based on the results of the ANOVA test in Table V, it becomes obvious that $\mathrm{F}$ between the two groups is 18.46 , where $\mathrm{p}=.000<0.05$. That is, the difference between the two groups is statistically significant. Hence, this study rejects the null hypothesis that reads "project-based training has no impact on students' translation competence" and accept the alternative hypothesis. The findings confirm that applying project-based training has a significant impact on students' translation competence.

\begin{tabular}{cccccc}
\multicolumn{7}{c}{ TABLE V: RESULTS OF THE ONE-WAY ANOVA TEST } \\
GLM DIFFERENCE BY GROUP \\
\hline \multicolumn{7}{c}{ Tests of Between-Subjects Effects } \\
\hline $\begin{array}{c}\text { Type III Sum of } \\
\text { Squares }\end{array}$ & df & $\begin{array}{c}\text { Mean } \\
\text { Square }\end{array}$ & F & Sig. \\
\hline Cource & 168,20 & 1 & 168,20 & 18,46 &, 000 \\
Model & 441,80 & 1 & 441,80 & 48,49 &, 000 \\
Intercept & 168,20 & 1 & 168,20 & 18,46 &, 000 \\
group & 164,00 & 18 & 9,11 & & \\
Error & 774,00 & 20 & & & \\
Total & 332,20 & 19 & & & \\
Corrected & & & & & \\
Total & &
\end{tabular}

\section{B. Analysis of the Structured Interviews}

To answer the second question of the study, "What are the perceptions of the students towards project-based training?", semi-structured interviews with the members of the experimental groups were conducted. The questions in the interviews aimed to investigate the students' perceptions of any effects of project-based learning on their translation competence. The questions covered the impact of projectbased learning on the student translators' bilingual competence, technological or instrumental competence, interpersonal, presentation and communication skills, and translation quality and management.

The participants agreed that project-based learning contributed to their training; they found that the projects are authentic and are related more to their lives and their future careers. In their view, the projects were highly motivating than the 'who'll take the next sentence' (WTNS) approach which is widely adopted in translator training institutions in the Arab World. They also stated that projects enhanced their confidence and familiarized them with various roles of translators such as editors, proof-readers, translators, project managers and the like. The diversity in roles was hailed by all the interviewees. In addition, the projects familiarized the students with various computer-aided translation tools, both desktop and web-based as well as various tools used in the translation industry such as subtitling, voice over, dubbing and localization tools. In addition, the projects enhanced the professional skills of the students. They consider them as golden opportunities to familiarize themselves with the nuts and bolts of the industry such as editing, translation standards and ethics as well as translation quality assessment and assurance. These are things they hardly find in the learning materials currently offered in their departments and they normally go unnoticed in the training programme. The interviewees also indicated that the projects developed their communication and negotiation skills, internet search skills and discovery learning. One of the interviewees indicated that before the course, dictionary and Microsoft Word were his ultimate instruments. The student acknowledged that the project-based approach adopted in the study taught him how to use several corpora tools. Those tools facilitated his work 
and helped him to find out how words really work in context. Interviews also emphasized that one of the advantages of the project-based learning adopted in the course resides in the fact that they were provided by hands-on tools which enabled them to prepare relevant glossaries, parallel and comparative corpora for their translation projects and to find the meanings of words, expressions, collocations and neologisms that can be hardly found in a dictionary.

In addition, the project-based learning in the translation classroom was viewed as stimulating students' independent work. Participants viewed the projects as problem-solution scenarios. The projects enhanced their strategic competence. They documented various grammatical, lexical, and pragmatic problems and they came up with solutions for them. They rarely came back to the lecturer whose role was mainly confined to facilitating the projects. The course also enhanced their self-efficacy beliefs. Student translators believed that they are more competent to undertake any translation, editing, proofreading and quality assurance managements roles with confidence. They have shown that they feel they are qualified to be part of the global translation industry. Other aspects highlighted by students include:

1. They realized the potential of the translation industry and market both locally and globally.

2. They did not only learn how to translate but how to manage translation.

3. They became more autonomous.

4. The projects enhanced their collaboration skills.

5. The projects enhanced their pre-editing and postediting skills.

\section{CONCLUSIONS}

The current study showed that project-based learning had a significant impact on enhancing the competence of translation trainees. In comparison to the results of the control group, the participants of the experimental group showed noticeable improvement in their results in post-testing in business translation. The participants' positive attitudes towards project-based learning and its impact on their translation competence was further supported by their responses in the interviews.

Project-based learning through practical and authentic tasks motivated students and enhanced their knowledge of the subject matter. Unlike a conventional classroom, projectbased learning promotes learner-centeredness, putting trainees at the center of the training. The projects represent a paradigm shift in the training of involved students. The approach has changed the roles of both teachers and students. The trainee is no longer a passive renderer of texts from one language to another; he or she is an active participant who can adopt various roles in a variety of projects. That is, trainees are the translators, proofreaders, revisers, editors, and the mangers of the project. They are fully responsible for the entire translation process and the quality assurance of the project. The projects are replicas of real translation work, and thus they enable the trainees to use various computer-assisted translation (CAT) tools, receive projects, and negotiate timing and financial requirements. In any translation project, clients need to be heard; their participation is essential when negotiating various aspects of the project, measuring the translation quality as well as many other skills that would not be possible without this mode of training. Moreover, the interviews with students showed that the project-based learning model adopted in the study enhances their communication and translation skills, promotes team spirit and self-discipline. Moreover, the approach enhances their confidence and autonomy in the learning process.

In a nutshell, constructing a framework of project-based learning and applying a proper assessment system have a great impact on the development of the translation competence of the would-be translators in a variety of dimensions and sub-competencies. In other words, the projects assist the translation trainees to enhance their bilingual, cultural, instrumental, physiological, and psychological sub-competencies.

\section{ACKNOWLEDGMENT}

The author thanks the anonymous reviewers for their valuable comments and suggestions to improve the quality of the paper.

\section{REFERENCES}

[1] R. Ellis, 'Position paper: Moving task-based language teaching forward', Lang. Teach., vol. 50, no. 4, pp. 507-526, 2017.

[2] M. Alkhatnai, 'Teaching Translation Using Project-Based-Learning: Saudi Translation Students Perspectives', AWEJ Transl. Lit. Stud. Vol., vol. 1, no. 4, pp. 83-94, 2017.

[3] R. E. Mitchell-Schuitevoerder, 'Translation and technology in a project-based learning environment.', Tralogy [En ligne], Session 3 Training translators / La formation du traducteur, Tralogy I, mis à jour le, May 21, 2014. http://lodel.irevues.inist.fr/tralogy/index.php?id=173.

[4] K. Herget, 'Project-based learning: A practical approach to implementing Memsource in the classroom', Val `encia, pp. 717-724, 2020.

[5] A. Szarkowska, 'A project-based approach to subtitler training', Linguist. Antverp. New Series-Themes Transl. Stud., vol. 18, 2019.

[6] M. Madkour, 'The Integration of Project-Based Methodology into Teaching in Machine Translation.', Int. Educ. Stud., vol. 9, no. 3, pp. 167-188, 2016.

[7] D. Li, C. Zhang, and Y. He, 'Project-based learning in teaching translation: Students' perceptions', Interpret. Transl. Train., vol. 9, no. 1 , pp. 1-19, 2015

[8] D. Apandi and S. S. Afiah, 'The use of project based learning in translation class', Acad. J. Perspect. Lang. Educ. Lit., vol. 7, no. 2, pp. 101-108, 2019.

[9] L. Deng, 'The Project-Based Flipped Learning Model in Business English Translation Course: Learning, Teaching and Assessment.', Engl. Lang. Teach., vol. 11, no. 9, pp. 118-128, 2018.

[10] M. Moghaddas and M. Khoshsaligheh, 'Implementing project-based learning in a Persian translation class: a mixed-methods study', Interpret. Transl. Train., vol. 13, no. 2, pp. 190-209, 2019.

[11] S. Bell, 'Project-based learning for the 21st century: Skills for the future', Clear. House, vol. 83, no. 2, pp. 39-43, 2010.

[12] M. González-Davies and V. Enríquez-Raído, 'Situated learning in translator and interpreter training: bridging research and good practice', Interpret. Transl. Train., vol. 10, no. 1, pp. 1-11, Jan. 2016, doi: 10.1080/1750399X.2016.1154339.

[13] S. Hansen-Schirra, S. Hofmann, and J. Nitzke, 'Acquisition of generic competencies through project simulation in translation studies', in Positive Learning in the Age of Information, Springer, pp. 267-280, 2018.

[14] T. Markham, 'Project based learning a bridge just far enough', Teach. Libr., vol. 39, no. 2, pp. 38-42, 2011.

[15] M. Havenga and H. De Beer, 'Project-based learning in consumer sciences: Enhancing students' responsibility in learning', J. Consum. Sci., vol. 44, pp. 58-70, 2016.

[16] A. J. Rotherman and D. T. Willingham, '21st century skills" not new but a worthy challenge', Am. Educ., vol. 34, no. 1, pp. 17-20, 2010.

[17] D. Kiraly, 'Growing a project-based translation pedagogy: A fractal perspective', Meta J. Traducteurs Meta Transl. J., vol. 57, no. 1, pp. 82-95, 2012. 